\title{
Expression of TRA2B in endometrial carcinoma and its regulatory roles in endometrial carcinoma cells
}

\author{
DHRUBA PAUDEL, YIQIN OUYANG, QINGTING HUANG, WEI ZHOU, JIANJUN WANG, \\ MAXWELL ENAYAT POOREKHORSANDI, BIPIN DHAKAL and XIAOWEN TONG
}

\author{
Department of Gynecology and Obstetrics, Tongji Hospital \\ Affiliated to Tongji University, Shanghai 200065, P.R. China
}

Received November 26, 2018; Accepted May 16, 2019

DOI: $10.3892 / 01.2019 .10553$

\begin{abstract}
Expression levels of Transformer 2 protein homolog beta (TRA2B) in patients with endometrial carcinoma were assessed to investigate the impact of TRA2B on endometrial carcinoma cells. Furthermore, we analyzed the expression of several genes in the tissue samples from patients with endometrial cancer (EC) to identify whether cancer related genes we chose are differently expressed between the endometrial carcinoma tissues and adjacent normal tissues. The results of RT-qPCR analysis, western blot technology and immunofluorescence method consistently manifested that the expression of several genes in endometrial carcinoma tissue was significantly dysregulated between the two groups. Among the dysregulated genes, the strongly upregulated TRA2B in the tissues and serum from patients with EC was selected for further analysis. Endometrial carcinoma cells were transfected with chemically synthesized TRA2B plasmid, siRNA-TRA2B and their corresponding negative control respectively to assess the effects of TRA2B on the EC cells. Overexpression of TRA2B increased both the cell viability and proliferation potency of EC cells. Whereas, the viability and the proliferation ability of EC cells were strongly decreased by siRNA-TRA2B treatment. Furthermore, the invasion of EC cells was promoted by transfection of TRA2B and overexpression of TRA2B decreased the apoptosis of EC cells. Moreover, siRNA-TRA2B transfection inhibited the invasion but accelerated apoptosis of EC cells. Our results demonstrated that TRA2B is closely related to the development of endometrial carcinoma, and inhibition of TRA2B can decrease viability, proliferation and invasion of endometrial carcinoma, suggesting TRA2B is associated with the pathogenesis of human EC. Knockdown of TRA2B may be used for treatment of endometrial carcinoma, furthermore,
\end{abstract}

Correspondence to: Dr Xiaowen Tong, Department of Gynecology and Obstetrics, Tongji Hospital Affiliated to Tongji University, 389 Xincun Road, Shanghai 200065, P.R. China

E-mail: dhruba627@126.com

Key words: endometrial cancer, transformer 2 protein homolog beta, proliferation, invasion, apoptosis these findings suggest an experimental foundation to clinical prognostic role of TRA2B in patients with endometrial carcinoma.

\section{Introduction}

Endometrial cancer (EC) arises from the uterine endometrium and accounts for the most common complex gynecological malignant tumor in the female reproductive system worldwide $(1,2)$. Statistical data have shown that the incidence of endometrial carcinoma dramatically increased in the past decades, and the morbidity of EC ranks second among female reproductive tract tumors (3-5). It is well established that the incidence of EC is predicted statistically to increase by $50-100 \%$ in 20 years according to parallel growth $(6,7)$. Several studies have shown dysregulated expression and function of genes in endometrial carcinoma (8-10). For example, LncRNA-FER1L4 notably decreases in EC and can suppress the proliferation of EC cells by targeting PTEN directly (11). In clinic, early and accurate prognosis is critical to the treatment and prognosis of patients with EC (12). Therefore, research discoveries of reliable and potential biomarkers and therapeutic candidates for early prognosis and preoperative identification of patients with endometrial carcinoma is urgent.

It is reported that incidence and development process of endometrial carcinoma involves various types of genes (13-16). Transformer 2 protein homolog beta (TRA2B), which has also been commonly known as SFRS10, is one of the SR protein family members (17). It is reported that TRA2B containing 419bp UCR to identify RNA motifs and has neighboring regions of serine residues as well as arginine residues resembling well characterized trans protein factors (18-20). In addition, TRA2B is highly and specially conserved across species including human, mouse, and others (21-23). Many studies have made clear that TRA2B plays a momentous role in a number of human cancers, including breast, ovarian, lung and cervical cancer (24-28). TRA2B has been shown to be connected with the viability, carcinogenesis and chemotherapeutic sensitivity of human cancer cells (29). Nevertheless, there are very few reports on the expression levels of TRA2B in the tissues and serum samples of patients with endometrial carcinoma and the roles of TRA2B in EC cells. Given the fact that TRA2B is implicated in various cancers, it is plausible to 
hypothesize that TRA2B may participate in the pathogenesis of endometrial carcinoma.

The biological and clinical relevance of TRA2B in EC progression and tumor metastasis is largely unknown. Therefore, the objective of this research was to characterize the expression levels of TRA2B in the tissues and blood collected from the patients with $\mathrm{EC}$ and the function feature of TRA2B in HEC-1B, an EC cell line. Our initial investigation found that the expression of TRA2B was dysregulated in EC patients. We hypothesized that the abnormal levels of TRA2B may lead to the incidence and course of EC. In order to further elucidate the function and effect of TRA2B in EC cells, we transfected EC cell line HEC-1B with synthetic TRA2B plasmid, siRNA-TRA2B\#1, siRNA-TRA2B\#2 and siRNA-TRA2B\#3. These results implied that the expression of TRA2B markedly increases in the tissues and serum of EC and TRA2B exhibited stimulative effects on the multiplication capacity and invasion ability of EC cells. Our findings therefore provide the first evidence that TRA2B is a critical tumor promoter in the development or progression of EC and supply a reliable biomarker and therapeutic targets for patients who suffer from EC. The potential role of TRA2B as a prognostic target needs to be further detected on a larger number of samples over longer time.

\section{Patients and methods}

Patients and tumor specimens. In total, 68 female patients admitted to the Department of Gynecology of Tongji Hospital Affiliated to Tongji University (Shanghai, China) from January, 2016 to December, 2017 with the pathological diagnosis of the EC tissues were selected as subjects, and the adjacent tissue samples were regarded as controls, which were acquired from the Department of Pathology of Tongji Hospital Affiliated to Tongji University. The age of patients ranged from 30 to 60 years (average age, $45.45 \pm 11.25$ years). All the procedures carried out conformed to the criteria of the International Federation of Gynecology and Obstetrics (FIGO staging system for uterine cancer, 2009) (30). The subjects had undergone surgical resections or biopsies at Tongji Hospital Affiliated to Tongji University, and the diagnoses were decided and determined by two or more gynaecologic pathologists. For patients with endometrial carcinoma, the EC tissues and normal tissues adjacent to cancer from the same patient were collected immediately in the operating theater from the removed uterus. The resected tissue samples were promptly treated with RNAlater (Vazyme) and frozen in liquid nitrogen container and ultimately stored in $-80^{\circ} \mathrm{C}$ freezer. All the experiments were repeated three times by using the tissues from donors.

In this study, patients who had corpus uteri or cervical inflammation, long term use of hormone drugs, other gynecological malignant tumors or suffered from preoperative chemotherapy, radiotherapy or biological targeted therapy were excluded from this investigation.

The present study was approved by the Ethics Committee of Tongji Hospital Affiliated to Tongji University. Patients who participated in this research had complete clinical data. The signed informed consents were obtained from the patients or the guardians.
Serum samples. The sera were collected from the 68 above-mentioned patients who were diagnosed with EC. The serum was age matched with healthy volunteers from Tongji Hospital Affiliated to Tongji University and were regarded as controls for statistical purpose. Healthy controls were women who were confirmed to have no history of cancer. Both patients and healthy volunteers were born in China, lived in the province of Heilongjiang, and aged 30-60 years. Approximately $15 \mathrm{ml}$ fresh blood from each subject was collected by using vacuum blood collection tube, and the serum was isolated and frozen immediately at $-80^{\circ} \mathrm{C}$. The serum of patients and control subjects was collected in parallel when possible. Clinical information was retrieved from medical records.

Cell culture. The human EC cell line HEC-1B (GDC129) was obtained from the China Center for Type Culture Collection. Human endometrial epithelial cell (HEEC) line (BSC-5110479756-01) was purchased from BioMart. The HEC-1B cells were transported in a box with dye ice and stored in a liquid nitrogen container or $-80^{\circ} \mathrm{C}$ freezer. When used HEC-1B was placed in a $37^{\circ} \mathrm{C}$ water bath (Prima) until $90 \%$ of ice thawed. The cells were then resuspended in $10 \mathrm{ml}$ volume of warm Dulbecco's modified Eagle's medium (DMEM; HyClone) in a $15 \mathrm{ml}$ centrifuge $\left(300 \mathrm{x} \mathrm{g}\right.$ at $4^{\circ} \mathrm{C}$ for $6 \mathrm{~min}$ ) (Thermo Fisher Scientific, Inc.). Afterwards, the cell pellet was plated and was allowed to attach in DMEM containing $10 \%$ fetal bovine serum (Invitrogen; Thermo Fisher Scientific, Inc.), $100 \mathrm{U} / \mathrm{ml}$ penicillin, $100 \mu \mathrm{g} / \mathrm{ml}$ streptomycin and optimal calcium ion. The resuscitated cells were grown in a $25 \mathrm{~cm}^{2}$ culture flask and placed at $37^{\circ} \mathrm{C}$ in a $5 \% \mathrm{CO}_{2}$ and $95 \%$ air humidified incubator (Thermo Fisher Scientific, Inc.). The culture solution was changed every two or three days. When the confluence reached $\sim 80-90 \%$, HEC-1B cells were detached with $0.25 \%$ trypsin based on the recommended instructions. HEC1-B cells in good condition were strictly plated in $25 \mathrm{~cm}^{2}$ cell culture flasks or 6 -well plates (Nest) at a density of $5.0 \times 10^{5}$ by using Countstar software (Thermo Fisher Scientific, Inc.). When the HEC1-B cells grew to $60-70 \%$ confluence, the cells were used for further experiments. The ESC cells were cultured in the specific culture medium (X-Y Technology) and maintained at $37^{\circ} \mathrm{C}$ in a $5 \% \mathrm{CO}_{2}$ and $95 \%$ air humidified incubator (Thermo Fisher Scientific, Inc.).

Plasmid transfection. Full-length cDNA of human TRA2B was subcloned into pHR'-puro vector, and the packaged TRA2B overexpressing plasmid and negative control (NC) lentivirus vector were obtained from GenePharma Co. To generate TRA2B overexpressing cells, BMSCs were treated with TRA2B plasmid. Aftercell plating in 6-well plates, and reaching $40-50 \%$ confluence transfection was performed. In most cases, plasmid vectors were used at $4 \mu \mathrm{g}$ in this study. Transfection of plasmid was strictly performed according to the protocol manual. Synthesized TRA2B plasmid, Lipofectamine 2000 and appropriate volume of fresh Opti-MEM Reduced Serum Medium (both from Thermo Fisher Scientific, Inc.) were used during transfection. After $6 \mathrm{~h}$ transfection of plasmid, the solution was changed with $2 \mathrm{ml}$ fresh cell medium with $10 \%$ FBS followed by further experiments. The expression of TRA2B in 
the EC cells after transfection of TRA2B plasmid for 24 was detected by RT-qPCR analysis.

Transfection of small interfering RNA. Lipofectamine 2000 transfection reagent (Thermo Fisher Scientific, Inc.) was used to transfect small interfering RNA TRA2B (siRNA-TRA2B) and was used for knocking down TRA2B and the NC into EC cells respectively. SiRNA-TRA2B and its NC was conducted (obtained from GenePharma Co). The protocol was performed in accordance with the manual instructions.

The HEC-1B were seeded into 6-well plates and transfection was conducted when the cell density reached $50-60 \%$. The cells were treated with Opti-MEM Reduced Serum Medium (Thermo Fisher Scientific, Inc.) containing siRNA-TRA2B at concentration of $50 \mathrm{nM}$ and $10 \mu \mathrm{l}$ volume of Lipofectamine 2000 for $6 \mathrm{~h}$. The cell supernatant was replaced with fresh medium and cells were cultured for $48 \mathrm{~h}$, then the transfected cells were harvested and used for further experiments. The control group was treated with $\mathrm{NC}$ following the same method. Three siRNAs, siRNA-TRA2B-1, siRNA-TRA2B-2 and siRNA-TRA2B-3, were designed to ensure the efficiency of the transfection. The following sequences of siRNA-TRA2B were used in this study; For TRA2B-1 forward: 5'-CCAGGCGUUCCAGAUCAAATT-3' and reverse: 5'-UUUGAUCUGGAACGCCUGGTT-3'; for TRA2B-2, forward: 5'-GCU AUGAUGAUCGGGACUATT-3' and reverse: 5'-UAGUCCCGAUCA UCAUAGCTT-3'; TRA2B-3, forward: 5'-CCAUUGCCGAUGUGUCUAUTT-3' and reverse: 5'-AUAGACACAUCGGCAAUGGTT-3'. The expression level of TRA2B in the EC cells treated with siRNA-TRA2B was assessed by RT-qPCR technology. We obtained three siRNAs that obviously knocked down TRA2B in HEC-1B cells.

RNA extraction. We validated the expression of TRA2B gene between the EC tissues and normal tissues from 68 participants with EC. The tissues were treated with RNAlater (Vazyme) and stored at $-80^{\circ} \mathrm{C}$ after isolation from patients. The serum of patients with EC and healthy volunteers were stored at $-80^{\circ} \mathrm{C}$. Total RNA was extracted from the tissues and serum into $1.5 \mathrm{ml}$ tubes containing $1 \mathrm{ml}$ volume of TRIzol reagent (Life Technology). The purity and the concentrations of the extracted RNA was analyzed and calculated by a NanoDrop 2000 machine (Thermo Fisher Scientific, Inc.), and only highly adequate and pure RNA $(>1.8 \mathrm{~A} 260 / \mathrm{A} 280<2.0)$ and RNA of good quality $(>200 \mathrm{ng} / \mathrm{ml})$ was used for additional analysis.

Reverse transcription. The reverse transcription procedure was carried out by using the High Capacity cDNA Reverse Transcription Kit (ABI). For reverse transcription, $0.5 \mu \mathrm{g}$ of total RNA was first treated with $1 \mu 1$ 10xRT buffer, $1 \mu \mathrm{l}$ random primer, $0.4 \mu \mathrm{l}$ deoxynucleoside Triphosphates (dNTPs) and $0.5 \mu 1$ reverse transcriptase based on published protocol. Autoclaved MilliQ water was added to $10 \mu \mathrm{l}$ volume. The cDNA was generated with the reaction condition of $95^{\circ} \mathrm{C}$ for $10 \mathrm{~min}$, 2 cycles at $37^{\circ} \mathrm{C}$ for $1 \mathrm{~h}, 85^{\circ} \mathrm{C}$ for $5 \mathrm{~min}$, and cooling at $4^{\circ} \mathrm{C}$. The generated cDNA was placed at $-20^{\circ} \mathrm{C}$ for further experiments.

Quantitative polymerase chain reaction ( $q P C R$ ). The resulting cDNA synthesis was then amplified by RT-qPCR method by using SYBR-Green PCR Master Mix (Vazyme). RT-qPCR analysis was set up by a Real-Time PCR Detection System (Roche Systems) by using a $20 \mu \mathrm{l}$ reaction composed of $1 \mu \mathrm{l}$ reverse transcription product, $10 \mu 1$ SYBR, $2 \mu 1$ Universal PCR Primer for specific genes and $7 \mu 1$ double distilled water. The conditions of the RT-qPCR were as follows: Denaturation at $95^{\circ} \mathrm{C}$ for $10 \mathrm{sec}, 40$ cycles at $95^{\circ} \mathrm{C}$ for $10 \mathrm{sec}$ and $55^{\circ} \mathrm{C}$ for $30 \mathrm{sec}$, finally cooling at $4^{\circ} \mathrm{C}$. The mRNA expression level of $18 \mathrm{~S}$ was used as internal controls for quantification of mRNA level of TRA2B gene. $\beta$-actin was used as reference, and the sequence of $\beta$-actin was: Forward, 5'-GGGAAATCGTGCG TGACATT-3' and reverse, 5'-GGAACCGCTCATTGCC AAT-3'. The primers were designed and obtained from GenePharma Co. The following primers were used to amplify specific genes: For TRA2B, forward: 5'-GCTCAGCCCAAA TACTCCAAG-3' and reverse: 5'-CATTCTCCCATGTCTAC TCGC-3'. For 18S, forward: 5'-GACCAGAGCGAAAAG CAT-3' and reverse: 5'-TCGGAACTACGACGGTATC-3'. The data were analyzed using the $2^{-\Delta \Delta \mathrm{Cq}}$ (31) relative expression method to calculate the level of relative TRA2B mRNA. The results were analyzed based on the sample threshold cycle (Cq) values from the experimentations which were repeated at least three times.

Western blot analysis. The western blot analysis was performed as previously reported (32). In short, the protein extracted from the EC tissues and adjacent normal tissues were obtained and resuspended in precooled radioimmunoprecipitation (RIPA) lysis buffer solution (Sigma-Aldrich; Merck KGaA) containing $200 \mathrm{mM} \mathrm{NaCl}, 2.5 \mathrm{mM} \mathrm{MgCl}$, $20 \mathrm{mM}$ Tris, $60 \mathrm{U} / \mathrm{ml}$ Superase-In, $1 \mathrm{mM}$ DTT and protease inhibitors (Roche Systems). BCA protein assay kit (Beyotime) was applied to determine the proteins. A total of $40 \mu \mathrm{g}$ of proteins were added per lane. After centrifugation at $2,000 \mathrm{xg}$, at $4^{\circ} \mathrm{C}$ for $\sim 30 \mathrm{~min}$, the liquid supernatant was transferred to $1.5 \mathrm{ml}$ sterilized tubes. Protein extracts $(50 \mu \mathrm{g})$ were separated by $12 \%$ sodium dodecyl sulfate (SDS)-polyacrylamide gel electrophoresis (PAGE; Beyotime). Next, the proteins were slowly transferred to an appropriate nitrocellulose membrane (EMD Millipore). The membrane was blocked in 5\% dry fat-free milk in tris-buffered saline (TBS) at room temperature for $\sim 2 \mathrm{~h}$. After milk saturation, the aforementioned membrane was incubated in diluted primary antibody against TRA2B (cat. no. sc-166829; dil, 1:500; Santa Cruz Biotechnology, Inc.) overnight with gentle shaking at $4^{\circ} \mathrm{C}$. The membrane was washed three times in TBS-Tween-20 buffer for $20 \mathrm{~min}$ on a shaking table, and subsequently incubated with appropriate secondary antibody goat anti-rabbit IgG (cat. no. A0286; dil, 1:1,000; Beyotime Institute of Biotechnology) at dil, 1:1,000 for $1 \mathrm{~h}$ at $4^{\circ} \mathrm{C}$. The protein bands were quantified using enhanced chemiluminescence western blot kit (ECL; Amersham Biosciences). TRA2B levels were normalized to $\beta$-actin (cat. no. sc-47778; dil, 1:500; Santa Cruz Biotechnology, Inc.). The expression of protein was visualized by ECL system (Cell Signaling Technology, Inc.). The level of proteins was analyzed using ImageJ software 1.50 (National Institutes of Health).

Immunohistochemistry. Immunohistochemistry was performed as described in a previous study (33). The paraffin embedded EC tissues and normal tissues from the same donors 
who met the requirements were collected. First, each tissue was fixed in $4 \%$ paraformaldehyde (PBS; Solarbio) for $48 \mathrm{~h}$. Next, $\sim 4 \mu \mathrm{m}$ consecutive paraffin sections were cut, heated, dewaxed and dehydrated with immunohistochemical method in accordance with the protocol. EDTA solution of $1 \mathrm{mM}$ $(\mathrm{pH}$ 8.9-9.1) was used for antigen retrieval and then endogenous peroxidase of tissues was removed. Then, sections were incubated in primary antibody dilution (antibody: PBS 1:500) against TRA2B (cat. no. sc-166829; dil, 1:500; Santa Cruz Biotechnology, Inc.) overnight at $4^{\circ} \mathrm{C}$ and washed by sterilized PBS at least 3 times. The tissues were then incubated in the presence of peroxidase-conjugated goat anti-rabbit antibody IgG which served as a secondary antibody (mouse, monoclonal, cat. no. A0286; dil, 1:1,000; Beyotime Institute of Biotechnology) at $37^{\circ} \mathrm{C}$ for $2 \mathrm{~h}$. Then, the sections were stained with diaminobenzidine (ZLI-9031) and counterstained with hematoxylin solution (ZLI-9643) (both from ZSGB-Bio). Ten different fields per group were randomly selected and recorded under a light microscope (Olympus Corp.).

Cell viability. The influence of TRA2B on the viability of HEC-1B cells was quantified by Cell Counting Kit-8 (CCK-8; Biotech) assay, and the procedure was performed as described previously (34). Briefly, HEC1-B cells were grown in 96-well plates (Labserv) at a density of $2.0 \times 10^{3}$ and maintained in DMEM medium. At $24 \mathrm{~h}$ after transfection, the cells in $96-$ well plates were incubated in $10 \mu \mathrm{lCCK}-8$ solution in $100 \mu \mathrm{l}$ DMEM medium without $\mathrm{FBS}$ at $37^{\circ} \mathrm{C}$ for $1,2,3$ and $4 \mathrm{~h}$. After gentle shaking for $1 \mathrm{~min}$, the absorbance values were detected and analyzed by using a microplate reader (BioTek Instruments) at $405 \mathrm{~nm}$ wavelength.

Cell proliferation. The proliferation of TRA2B was measured by Tetrazolium (MTT) method. 3.0x10 $0^{3}$ HEC1-B cells per well were plated in 96-well plates (Corning, Inc.) with $500 \mu \mathrm{l}$ culture medium composed of $10 \%$ FBS and incubated in a cell incubator. At $0,12,24$ and $48 \mathrm{~h}$ after seeding, the cells were treated with $20 \mu \mathrm{l}$ MTT solution (Solarbio) at a concentration of $5 \mathrm{mg} / \mathrm{ml}$ for $\sim 4 \mathrm{~h}$. After $4 \mathrm{~h}$ incubation, the solution was discharged, and precipitated formazan was dissolved in $150 \mu \mathrm{l}$ volume of dimethyl sulfoxide (DMSO). After gentle shaking for $2 \mathrm{~min}$, the OD values at $490 \mathrm{~nm}$ were assessed by a microplate reader (BioTek Instruments). Blank values obtained from wells containing only media were subtracted.

TUNEL staining. The anti-apoptotic effects of TRA2B on the EC cell were analyzed by TUNEL staining. In Situ cell death detection kit (POD)/TUNEL was purchased from Roche Corporation. The following steps were performed referring to the protocol. Briefly, EC cells were rinsed with cool PBS three times and fixation was performed in 4\% PFA solution for 20-30 min. Then, the cells were thoroughly permeabilized by $0.1 \%$ Triton X-100 (Biosharp). Cells were then incubated in $500 \mu \mathrm{l}$ TUNEL reaction mixture for $2 \mathrm{~h}$ at $37^{\circ} \mathrm{C}$ in the dark. Finally, the nucleus were stained by DAPI solution (Solarbio) for $30 \mathrm{~min}$ in the dark. The number of apoptotic cells was determined under an optical microscope (Olympus Corp.). For each well, more than ten random areas of TUNEL-stained cells were captured and counted. The percentage of apoptotic cells was determined from TUNEL-positive cells relative to
DAPI-stained cells. The sections were fixed in $4 \%$ paraformaldehyde (PBS; Solarbio) at room temperature for $48 \mathrm{~h}$. The staining concentration was 1:500, at room temperature.

Transwell cell invasion assay. The in vitro invasion ability of the EC cell line was analyzed as previously described (35). In brief, we used $8-\mu \mathrm{m}$ pore Transwell cell culture chambers (Corning, Inc.) coated with $30 \mu \mathrm{l}$ specific Matrigel (BD Biosciences) which served as a reconstituted basement membrane for the invasion assay. Cells $\left(2 \times 10^{4}\right)$ were plated in upper chamber. The cells were then resuspended in $200 \mu \mathrm{l}$ DMEM medium without FBS and placed in the top compartment of the Transwell chambers. Then, optimal volume of standard culture medium (10\% FBS), which was regarded as chemoattractant, was added into the lower chamber and the staining was performed at room temperature. After $24 \mathrm{~h}, \mathrm{EC}$ cells on the upper surface were carefully removed by a clean cotton swab. After removing the non-invasive cells, the cells at the bottom of the lower chamber were harvested and fixed in 4\% PFA (PBS; Solarbio) for $30 \mathrm{~min}$. After PBS washing, the cells were stained with $0.1 \%$ crystal violet solution (Biosharp) for $\sim 30 \mathrm{~min}$. After rinsed in PBS for $10 \mathrm{~min}$, the total number of invasive cells was accurately detected under an Olympus fluorescence microscope (Olympus Corp.). The total number was counted by using AIS software.

Statistical analysis. Data were analyzed using SPSS 21.0 software (IBM). The data were representative of similar results which were repeated at least three times. Results were expressed as mean $\pm \mathrm{SD}$. The differences among multiple groups were analyzed by ANOVA followed by the Fisher's test, and between two groups were compared by Student's t-test. Paired t-test was used for the comparisons between paired samples. One-way analysis of variance was used for the comparisons between multiple samples. A value of $\mathrm{P}<0.05$ was considered as statistically significant.

\section{Results}

Identification of differentially expressed genes. To discover a key gene which plays a critical role in the progression of EC, we chose several cancer related genes from previous studies (36-38), and identified the expression of these genes in 68 pairs of EC tissues and paired normal tissues. The genes were recently reported to be differentially expressed in tumor tissues and associated to the progression and metastasis of cancer. However, the relationship between these genes and EC is not fully explored. In this study, RT-qPCR was performed to detect the relative mRNA levels of these genes. The results showed that SNCA, PLZF, AZGP1 and PHD2 were commonly downregulated and D-dimer, PD-L1, TRA2B, HIF-1 $\alpha$ and CYR61 increased in the tissue of patients with ECs (Fig. 1A and B). However, the expression of SR-BI, cytokeratin 14, CXCL7, MUC13, CD83 was not associated with EC (Fig. 1C). Based on these differentially expressed genes in EC, we finally selected 3 upregulated genes including TRA2B, CYR61 and HIF-1 $\alpha$ for further analysis.

Expression of TRA2B in endometrial carcinoma tissues. To investigate the protein expression of TRA2B, CYR61 and 

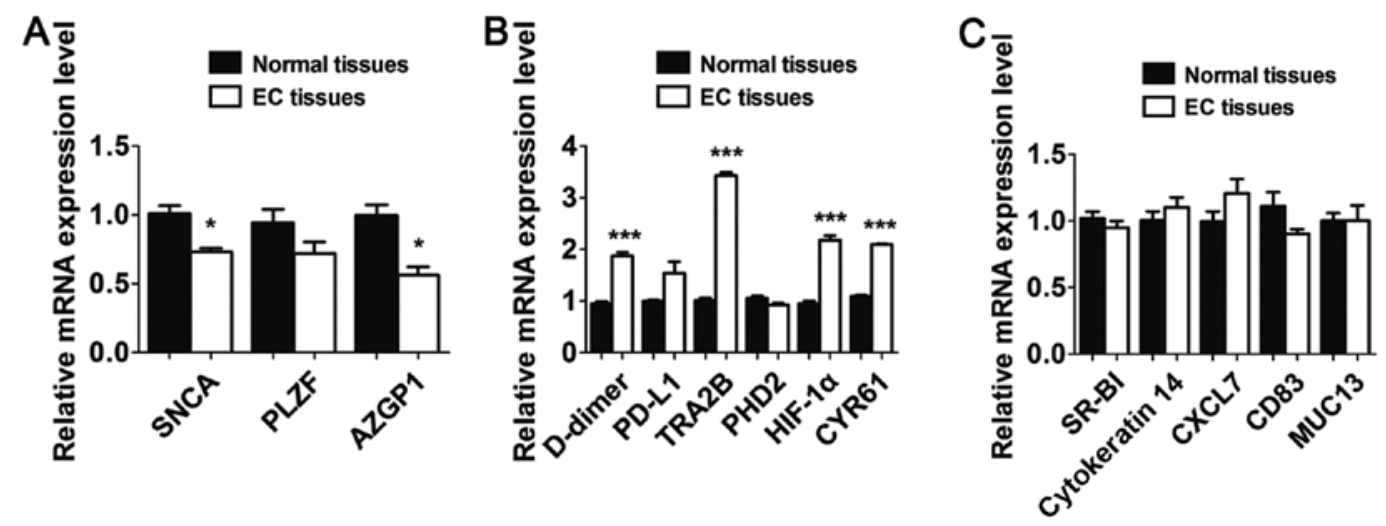

Figure 1. The expression of cancer related genes in the tissues of patients with EC. The relative expression of cancer related genes in EC tissues compared with controls. Results are presented as the mean \pm standard deviation. ${ }^{*} \mathrm{P}<0.05,{ }^{* * * *} \mathrm{P}<0.001$ compared with the control group. (A) SNCA, PLZF, AZGP1 and PHD2 were commonly downregulated in EC tissue compared with control group. "P<0.05. (B) D-dimer, PD-L1, TRA2B, HIF-1 $\alpha$ and CYR61 increased in the tissue of patients with ECs compared with control group. ${ }^{* * *} \mathrm{P}<0.001$. (C) The difference of expression of SR-BI, cytokeratin 14, CXCL7, MUC13, CD83 between ECs and control group were not significantly different $(\mathrm{P}>0.05)$.

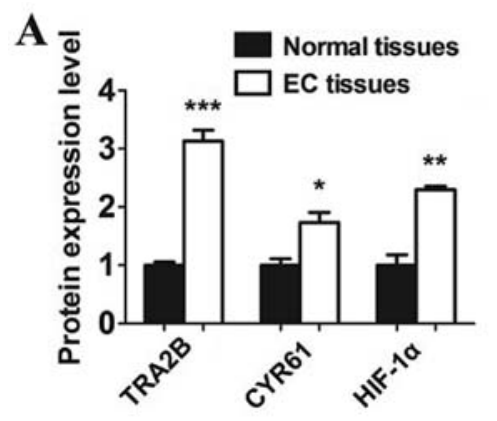

B

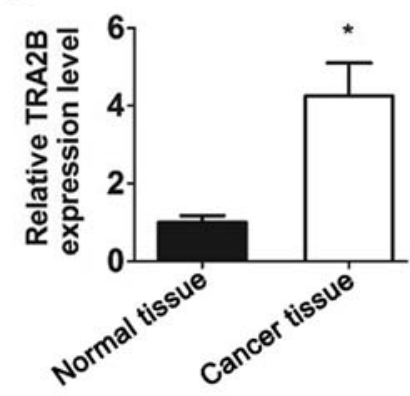

C

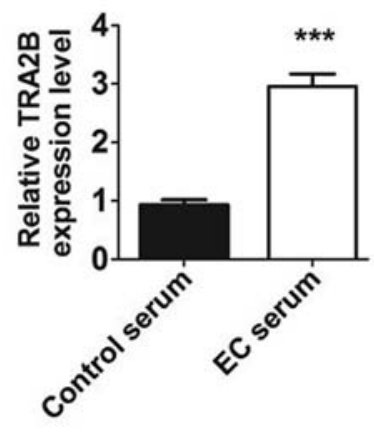

EC tissues

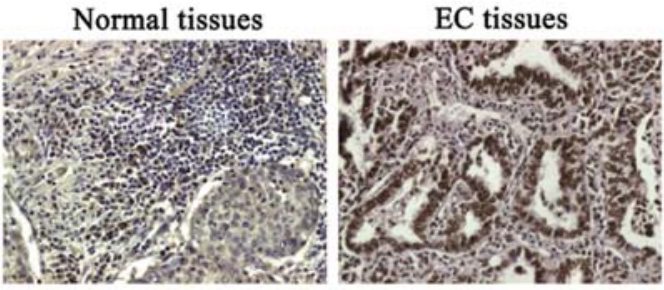

Figure 2. High levels of TRA2B in EC tissues of patients. (A) Western blot analysis data confirmed that the protein levels of three genes were augmented in the tissue of EC. (B) Immunohistochemistry results indicate that TRA2B was greatly higher in endometrial carcinoma tissues relative to normal tissue. Results are from three or more independent experiments. Scale bar, $100 \mu \mathrm{m}$. (C) The expression of TRA2B in the serum of patients with EC was measured by RT-qPCR technology. Data are the mean \pm standard deviation. ${ }^{*} \mathrm{P}<0.05,{ }^{* *} \mathrm{P}<0.01,{ }^{* * *} \mathrm{P}<0.001$, compared with the control group.

HIF-1 $\alpha$, western blot (WB) assay was applied to determine the protein expression of the three genes that exhibited dysregulated expression between EC tissues and normal tissues. As shown in the results, the expression of TRA2B, CYR61 and HIF-1 $\alpha$ was significantly increased in the EC tissues relative to normal tissues (Fig. 2A). Specifically, TRA2B showed at least a 3-fold change in expression between these groups. Therefore, among them, TRA2B was the most significantly upregulated gene in EC tissues.

Immunohistochemistry results indicated that 68 cases of EC subjects showed positive expression of TRA2B. The expression of TRA2B in EC tissue was greatly higher than that in normal tissue $(\mathrm{P}<0.05)$ (Fig. 2B).

We also detected the expression of TRA2B in the serum sample of patients with EC and healthy volunteers. The increased levels of TRA2B in the patients with EC was measured by RT-qPCR (Fig. 2C). Taken together, our results therefore indicated that TRA2B was seen to be closely related to $\mathrm{EC}$ and had the potential of oncogenicity.

Knockdown of TRA2B inhibits the viability and proliferation of EC cells. The aforementioned data suggest that TRA2B expression was positively associated with EC. Based on the above-mentioned experimental results, we hypothesized that TRA2B may affect the proliferation and invasion of EC cells. Thus, we continue to detect the roles of TRA2B on the progression of EC cells to test this hypothesis.

Initially, to explore the effect of TRA2B on the viability of EC cells, the EC cells were cultured and used for analysis on the expression of TRA2B. The morphological images 

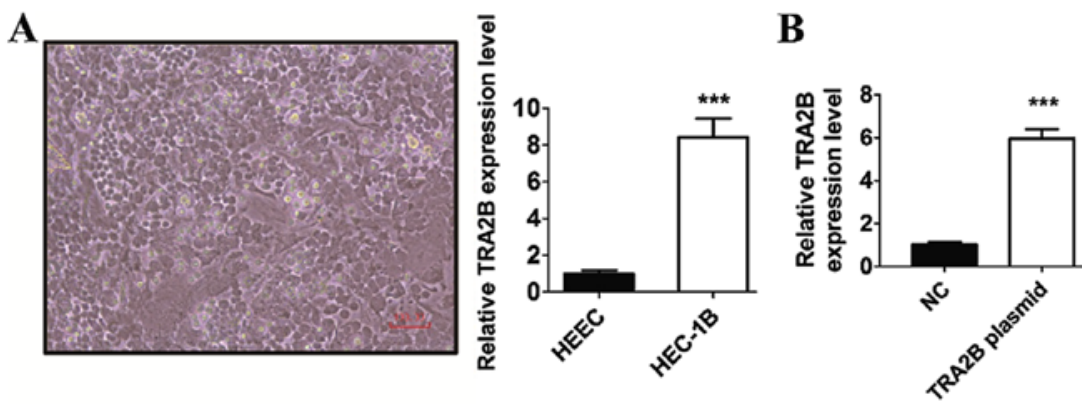

C
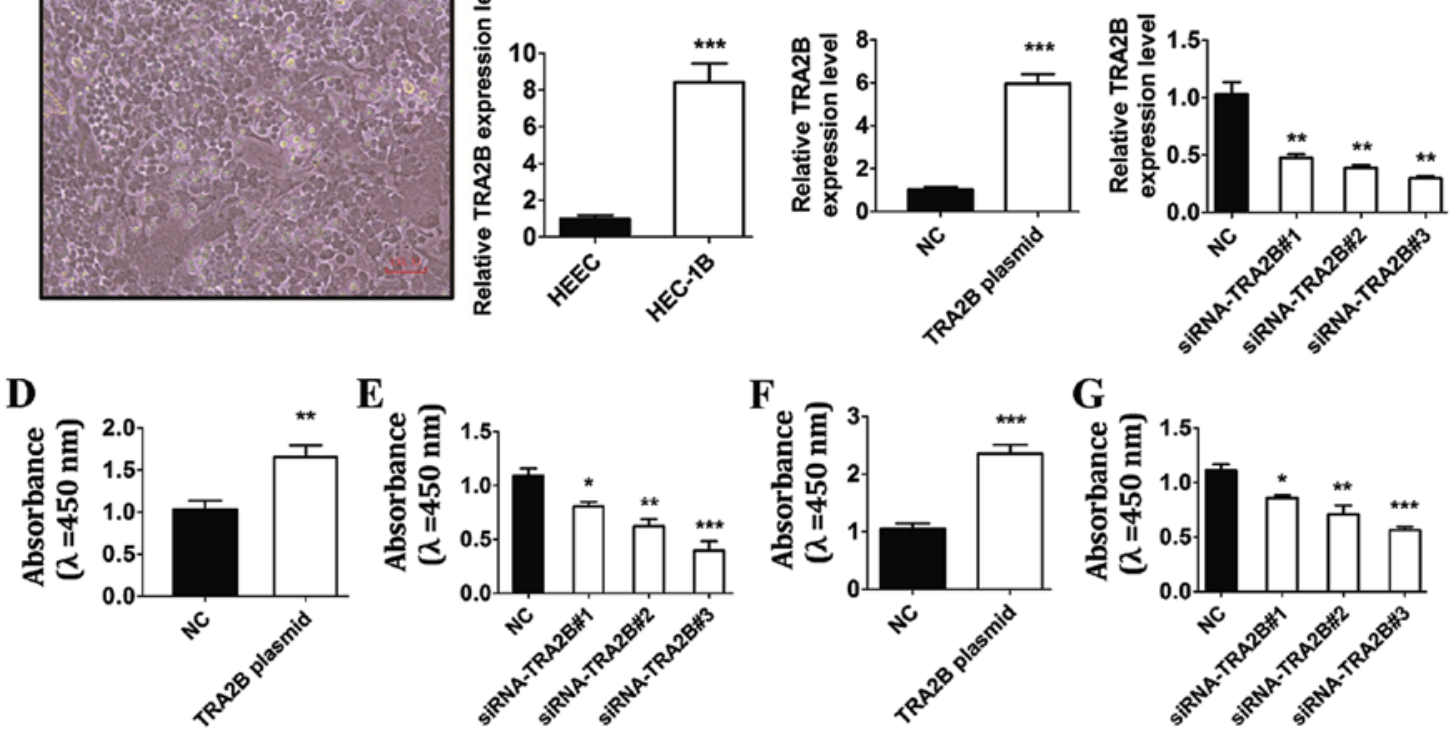

Figure 3. TRA2B regulates the viability and proliferation of EC cells. (A) The morphological images of EC cells and the expression of TRA2B in EC cells. Scale bar, $100 \mu \mathrm{m}$. (B) The significantly elevated expression of TRA2B in EC cells after transfection of TRA2B plasmid was detected by RT-qPCR. (C) RT-qPCR analysis indicates that siRNA-TRA2B decreased the expression of TRA2B compared to the corresponding control. (D and E) CCK-8 assay assessed that cell viability of EC cells was reduced by siRNA-TRA2B and increased by TRA2B overexpression. (F) Overexpression of TRA2B accelerated the proliferation potential of EC cells. (G) The decrease in the proliferation of EC cells which was induced by siRNA-TRA2B was quantified by MTT assay. Results are representative of three independent experiments. ${ }^{*} \mathrm{P}<0.05,{ }^{* *} \mathrm{P}<0.01,{ }^{* * * *} \mathrm{P}<0.001$, was considered highly significant, compared with control.

of EC cells are shown in Fig. 3A, and the expression of TRA2B was significantly increased in EC cells compared with human endometrial epithelial cells (HEEC) (Fig. 3A). We treated EC cells with TRA2B plasmid, siRNA-TRA2B and its corresponding NC. RT-qPCR results showed that EC cells exhibited high expression of TRA2B after transfection of TRA2B plasmid (Fig. 3B). As shown in Fig. 3B, RT-qPCR analysis indicated that the expression of TRA2B was low in EC cells after transfection of siRNA-TRA2B\#1, siRNA-TRA2B\#2, siRNA-TRA2B\#3 compared with the NC group for $24 \mathrm{~h}$ (Fig. 3C).

Next, we treated EC cells with TRA2B plasmid, siRNA-TRA2B\#1, siRNA-TRA2B\#2, siRNA-TRA2B\#3 and $\mathrm{NC}$ for $24 \mathrm{~h}$ and detected the role of TRA2B in the cell viability of HEC-1B cells by cell counting kit- 8 assay. As can be seen in Fig. 3D and E, the viability of EC cells was extremely augmented by TRA2B plasmid. In contrast, transfection with three siRNA-TRA2B for $24 \mathrm{~h}$ led to marked reduction of viability in EC cells compared with the corresponding controls, suggesting that inhibition of TRA2B attenuates the cell viability of EC cells (Fig. 3D and E).

The effect of TRA2B was probed on the proliferation capacity of EC cells by MTT assay. As Fig. 3F shows, the proliferation of EC cells increased after transfection of TRA2B. Whereas, BMSCs transfected with siRNA-TRA2B exhibited significantly lower absorbance values in comparison with the control group, which indicated siRNA-TRA2B-induced decline in the proliferation of EC cells (Fig. 3G). These results indicated that TRA2B silencing caused a suppression on the viability and proliferation of EC cells.

Suppression of TRA2B reduces invasion and facilitates apoptosis of EC cells. The results above suggest that TRA2B was positively associated with the cell viability and proliferation of EC cells. To prove out hypothesis, we treated HEC-1B cells with TRA2B plasmid and siRNA-TRA2B to investigate whether it can affect the invasiveness of EC cells by Transwell invasion assay. The results suggested that cells transfected with TRA2B plasmid exhibited stronger ability to invade in comparison with NC (Fig. 4A). Furthermore, the Transwell results displayed that the number of cells which passed through the basement membrane was significantly reduced after interference of the TRA2B gene with siRNA-TRA2B, indicating that suppression of TRA2B significantly reduced the invasion ability of EC cells (Fig. 4B). These data demonstrated an inhibitory role for siRNA-TRA2B in the invasiveness of EC cells.

To examine whether TRA2B could affect the apoptosis of EC cells, we treated EC cells with TRA2B and siRNA-TRA2B and stained the cells with TUNEL staining. The nucleus was stained with DAPI solution for counting. As demonstrated in Fig. 4C, overexpression of TRA2B attenuated apoptotic cells compared with NC group. Moreover, TRA2B silencing significantly increased apoptosis of EC cells relative to the corresponding control group (Fig. 4D). Consistently, TRA2B decreased apoptosis of the EC cells. The data validated that silencing of TRA2B promotes apoptosis of EC cells.

\section{Discussion}

Several genes have been recently investigated and found to be differentially expressed in tumors and involved in the progression and metastasis of human cancers (39-41). For example, it is reported that ENO1 was confirmed as an upregulated protein in uterine aspirate samples of patients with EC (42). Increasing evidence has also reported on the relationship 
A

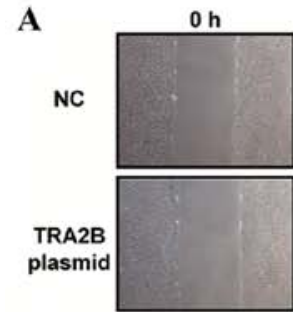

B

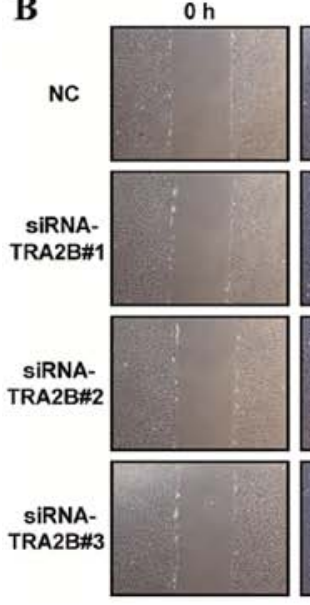

$24 \mathrm{~h}$

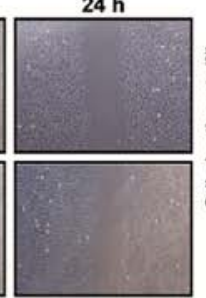

$24 \mathrm{~h}$
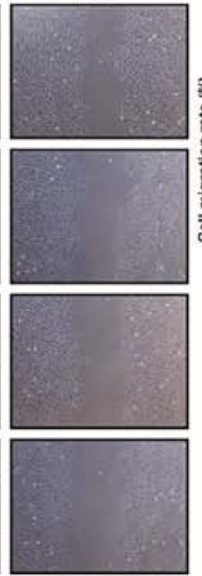

C
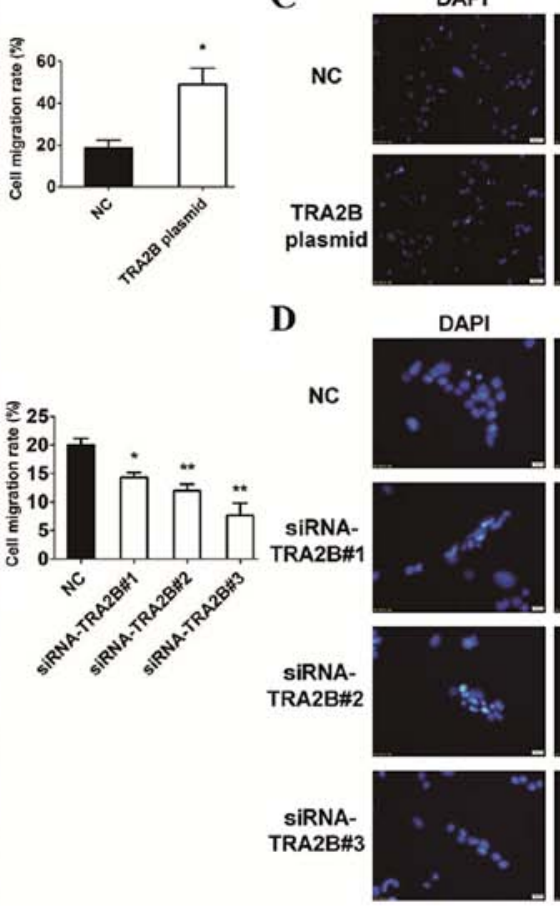

DAPI

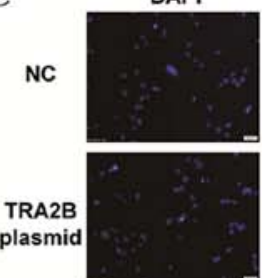

D

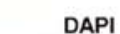

TUNEL
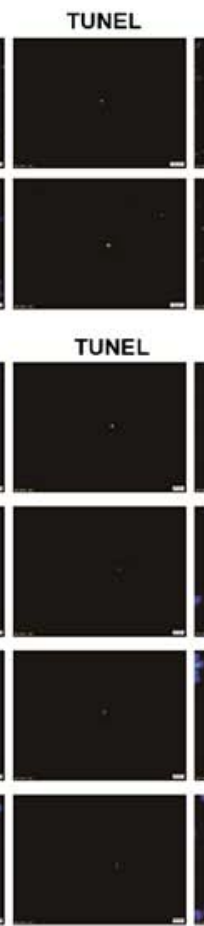
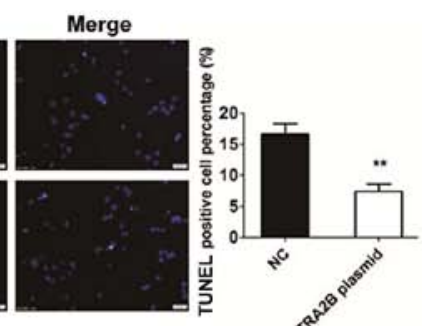

Merge
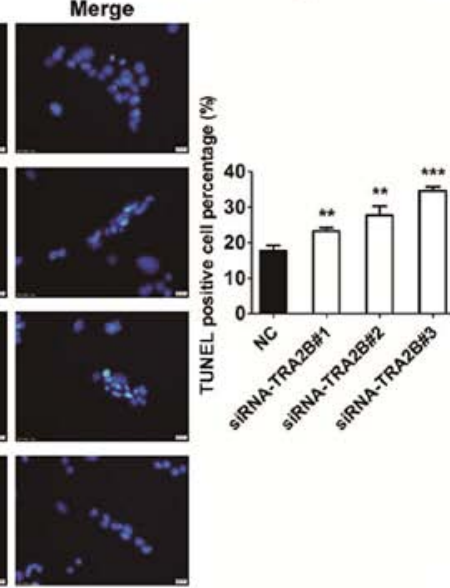

Figure 4. The role of TRA2B on the invasion and apoptosis of EC cells. (A and B) Transwell invasion results demonstrate that the invasion ability is decreased by silence of TRA2B, while increased by TRA2B plasmid compared with the NC group. Parts A and B: Scale bar, $100 \mu \mathrm{m}$. (C) The increase in the total number of TUNEL-stained cells caused by TRA2B overexpression was determined by the staining. (D) TUNEL staining determined that depletion of TRA2B decreases the proliferation ability of EC cells. Parts $C$ and D: Scale bar, $200 \mu \mathrm{m} .{ }^{*} \mathrm{P}<0.05,{ }^{* *} \mathrm{P}<0.01,{ }^{* * * *} \mathrm{P}<0.001$, compared with the control group.

between TRA2B expression and several diseases and cancers, and high expression of TRA2B has been linked to aggressive disease and poor survival in cancer (43-46). However, little is known of the effects of TRA2B on the progression and invasion of EC.

In this study, we first analysed the expression of TRA2B in the tissue of patients with EC. We only identified the expression of the genes which have been discovered to be connected with cancer. Our data indicated that among them, the expression level of TRA2B in the tissue of patients with EC was greatly higher than that in the normal tissue. It would be interesting to further explore whether high TRA2B expression could be used to select patients with EC. We hypothesized that TRA2B may be associated with EC and even affect the cell viability, proliferation, invasion and apoptosis of EC cells. In this study, CCK-8 assay showed that the knockdown of TRA2B by the siRNA in EC cells was observed to reduce cell viability. Downregulation of TRA2B inhibits the proliferation of EC cells. Furthermore, the invasion capacity of EC cells was decreased after treatment with TRA2B silencing in contrast to control group. Loss of the TRA2B in EC cells enhances cell apoptosis which was detected by TUNEL staining. Our data validation declared that knockdown of TRA2B reduces cell viability, proliferation, invasion of EC cells, but induces apoptosis of EC cells. The present study provided an independent prognostic marker in endometrial carcinoma.

In the present study, our data manifested high expression of TRA2B in 68 EC patients. However, it is difficult to study novel biomarkers in serum or plasma due to dynamic range and the low concentration of biomarkers. This research focused on the tissues and serum of patients with EC and healthy volunteers.
The strength of this study is the large cohort, including 68 evaluable patients with EC. This gene has the potential to be a critical biomarker and target for all patients with EC.

Taken together, our results present molecular biological evidence of the association between TRA2B and EC and reveal the role of TRA2B in EC cells. The results of this study suggest that TRA2B can promote cell viability, proliferation and invasion in EC. It is important to study the association of TRA2B with EC. The clinical application of TRA2B as a potential molecular biomarker for EC can increase the diagnostic process, reduce medical expenses, and improve the quality of life.

\section{Acknowledgements}

Not applicable.

\section{Funding}

No funding was received.

\section{Availability of data and materials}

The datasets used and/or analyzed during the current study are available from the corresponding author on reasonable request.

\section{Authors' contributions}

DP, XT, YO wrote the manuscript. DP and YO helped with cell culture and transfection. QH and WZ were responsible for RNA transfection. JW and MEP performed RT-qPCR. BD and 
XT contributed to immunohistochemistry and MTT assay. All the authors read and approved the final manuscript.

\section{Ethics approval and consent to participate}

The present study was approved by the Ethics Committee of Tongji Hospital Affiliated to Tongji University (Shanghai, China). Patients who participated in this research had complete clinical data. The signed informed consents were obtained from the patients or the guardians.

\section{Patient consent for publication}

Not applicable.

\section{Competing interests}

The authors declare that they have no competing interests.

\section{References}

1. Garg K, Karnezis AN and Rabban JT: Uncommon hereditary gynaecological tumour syndromes: Pathological features in tumours that may predict risk for a germline mutation. Pathology 50: 238-256, 2018.

2. Seagle BL, Alexander AL, Lantsman T and Shahabi S: Prognosis and treatment of positive peritoneal cytology in early endometrial cancer: Matched cohort analyses from the National Cancer Database. Am J Obstet Gynecol 218: 329.e1-329.e15, 2018.

3. Pal N, Broaddus RR, Urbauer DL, Balakrishnan N, Milbourne A, Schmeler KM, Meyer LA, Soliman PT, Lu KH, Ramirez PT, et al: Treatment of low-risk endometrial cancer and complex atypical hyperplasia with the levonorgestrel-releasing intrauterine device. Obstet Gynecol 131: 109-116, 2018.

4. Troisi J, Sarno L, Landolfi A, Scala G, Martinelli P, Venturella R, Di Cello A, Zullo F and Guida M: Metabolomic signature of endometrial cancer. J Proteome Res 17: 804-812, 2018.

5. Smith D, Stewart CJR, Clarke EM, Lose F, Davies C, Armes J, Obermair A, Brennan D, Webb PM, Nagle CM, et al: ER and PR expression and survival after endometrial cancer. Gynecol Oncol 148: 258-266, 2018.

6. Gibson DA, Collins F, Cousins FL, Esnal Zufiaurre A and Saunders PT: The impact of 27-hydroxycholesterol on endometrial cancer proliferation. Endocr Relat Cancer 25: 381-391, 2018.

7. Cho K, Havelock JC, Gilks B and Dunne C: Case report: An identical twin with Sertoli-Leydig cell tumor. Gynecol Endocrinol 34: 563-566, 2018.

8. Deguine C and Pulec JL: Attic cholesteatoma and tympanosclerosis. Ear Nose Throat J 76: 364, 1997.

9. Wen KC, Sung PL, Chou YT, Pan CM, Wang PH, Lee OK and $\mathrm{Wu} \mathrm{CW}$ : The role of EpCAM in tumor progression and the clinical prognosis of endometrial carcinoma. Gynecol Oncol 148: 383-392, 2018

10. Hou R, Yao SS, Liu J, Wang LL, Wu L and Jiang L: Dietary n-3 polyunsaturated fatty acids, fish consumption, and endometrial cancer risk: A meta-analysis of epidemiological studies. Oncotarget 8: 91684-91693, 2017.

11. Qiao Q and Li H: LncRNA FER1L4 suppresses cancer cell proliferation and cycle by regulating PTEN expression in endometrial carcinoma. Biochem Biophys Res Commun 478: 507-512, 2016.

12. Williams E, Villar-Prados A, Bowser J, Broaddus R and Gladden AB: Loss of polarity alters proliferation and differentiation in low-grade endometrial cancers by disrupting Notch signaling. PLoS One 12: e0189081, 2017.

13. Maybin JA, Murray AA, Saunders PT, Hirani N, Carmeliet P and Critchley HO: Hypoxia and hypoxia inducible factor- $1 \alpha$ are required for normal endometrial repair during menstruation. Nat Commun 9: 295, 2018.

14. Knific T, Vouk K, Smrkolj Š, Prehn C, Adamski J and Rižner TL: Models including plasma levels of sphingomyelins and phosphatidylcholines as diagnostic and prognostic biomarkers of endometrial cancer. J Steroid Biochem Mol Biol 178: 312-321, 2018.
15. Beck TL, Schiff MA, Goff BA and Urban RR: Robotic, laparoscopic, or open hysterectomy: Surgical outcomes by approach in endometrial cancer. J Minim Invasive Gynecol 25: 986-993, 2018.

16. Ebeid K, Meng X, Thiel KW, Do AV, Geary SM, Morris AS, Pham EL, Wongrakpanich A, Chhonker YS, Murry DJ, et al: Synthetically lethal nanoparticles for treatment of endometrial cancer. Nat Nanotechnol 13: 72-81, 2018.

17. Pihlajamäki J, Lerin C, Itkonen P, Boes T, Floss T, Schroeder J, Dearie F, Crunkhorn S, Burak F, Jimenez-Chillaron JC, et al: Expression of the splicing factor gene SFRS10 is reduced in human obesity and contributes to enhanced lipogenesis. Cell Metab 14: 208-218, 2011.

18. Grellscheid SN, Dalgliesh C, Rozanska A, Grellscheid D, Bourgeois CF, Stévenin J and Elliott DJ: Molecular design of a splicing switch responsive to the RNA binding protein Tra2 $\beta$. Nucleic Acids Res 39: 8092-8104, 2011.

19. Hirschfeld M, Jaeger M, Buratti E, Stuani C, Grueneisen J, Gitsch $\mathrm{G}$ and Stickeler E: Expression of tumor-promoting Cyr61 is regulated by hTRA2- $\beta 1$ and acidosis. Hum Mol Genet 20: 2356-2365, 2011

20. Elks CE, Perry JR, Sulem P, Chasman DI, Franceschini N, He C, Lunetta KL, Visser JA, Byrne EM, Cousminer DL, et al; GIANT Consortium: Thirty new loci for age at menarche identified by a meta-analysis of genome-wide association studies. Nat Genet 42: 1077-1085, 2010.

21. Mende Y, Jakubik M, Riessland M, Schoenen F, Rossbach K, Kleinridders A, Köhler C, Buch T and Wirth B: Deficiency of the splicing factor Sfrs10 results in early embryonic lethality in mice and has no impact on full-length SMN/Smn splicing. Hum Mol Genet 19: 2154-2167, 2010.

22. Benderska N, Becker K, Girault JA, Becker CM, Andreadis A and Stamm S: DARPP-32 binds to tra2-beta1 and influences alternative splicing. Biochim Biophys Acta 1799: 448-453, 2010.

23. Grellscheid S, Dalgliesh C, Storbeck M, Best A, Liu Y, Jakubik M, Mende Y, Ehrmann I, Curk T, Rossbach K, et al: Identification of evolutionarily conserved exons as regulated targets for the splicing activator tra2 $\beta$ in development. PLoS Genet 7: e1002390, 2011.

24. Gabriel B, Zur Hausen A, Bouda J, Boudova L, Koprivova M, Hirschfeld M, Jager M and Stickeler E: Significance of nuclear hTra2-beta1 expression in cervical cancer. Acta Obstet Gynecol Scand 88: 216-221, 2009.

25. Watermann DO, Tang Y, Zur Hausen A, Jäger M, Stamm S and Stickeler E: Splicing factor Tra2-beta1 is specifically induced in breast cancer and regulates alternative splicing of the CD44 gene. Cancer Res 66: 4774-4780, 2006.

26. Yang M, Li L, Wang J, Gao T, Sun Y, Li H, Tong X and Ouyang Y: Heterogeneous nuclear ribonucleoproteins (hnRNPs) and human transformer-2-beta1 (hTra2-beta1)-regulated estrogen receptor-alpha improves prognosis of endometrial cancer. Eur J Gynaecol Oncol 35: 701-707, 2014

27. Akaike Y, Masuda K, Kuwano Y, Nishida K, Kajita K, Kurokawa K, Satake Y, Shoda K, Imoto I and Rokutan K: HuR regulates alternative splicing of the TRA $2 \beta$ gene in human colon cancer cells under oxidative stress. Mol Cell Biol 34: 2857-2873, 2014.

28. Kajita K, Kuwano Y, Satake Y, Kano S, Kurokawa K, Akaike Y, Masuda K, Nishida K and Rokutan K: Ultraconserved region-containing Transformer $2 \beta 4$ controls senescence of colon cancer cells. Oncogenesis 5: e213, 2016.

29. Munkley J, Livermore K, Rajan P and Elliott DJ: RNA splicing and splicing regulator changes in prostate cancer pathology. Hum Genet 136: 1143-1154, 2017.

30. Petru E, Lück HJ, Stuart G, Gaffney D, Millan D and Vergote I; Gynecologic Cancer Intergroup (GCIG): Gynecologic Cancer Intergroup (GCIG) proposals for changes of the current FIGO staging system. Eur J Obstet Gynecol Reprod Biol 143: 69-74, 2009.

31. Livak KJ and Schmittgen TD: Analysis of relative gene expression data using real-time quantitative PCR and the 2(-Delta Delta C(T)) method. Methods 25: 402-408, 2001.

32. Wang QW, Su Y, Sheng JT, Gu LM, Zhao Y, Chen XX, Chen C, Li WZ, Li KS and Dai JP: Anti-influenza A virus activity of rhein through regulating oxidative stress, TLR4, Akt, MAPK, and NF-kappaB signal pathways. PLoS One 13: e0191793, 2018.

33. Gu Y, Zhang J and Guan H: Expression of EZH2 in endometrial carcinoma and its effects on proliferation and invasion of endometrial carcinoma cells. Oncol Lett 14: 7191-7196, 2017. 
34. Zhang J, Pi J, Liu Y, Yu J and Feng T: Knockdown of YTH N6-methyladenosine RNA binding protein 2 (YTHDF2) inhibits proliferation and promotes apoptosis in MGC-803 gastric cancer cells. Xi Bao Yu Fen Zi Mian Yi Xue Za Zhi 33: 1628-1634, 2017 (In Chinese)

35. Liu J, Qu X, Shao L, Hu Y, Yu X, Lan P, Guo Q, Han Q, Zhang J and Zhang C: Pim-3 enhances melanoma cell migration and invasion by promoting STAT3 phosphorylation. Cancer Biol Ther 19: 160-168, 2018

36. Grilz E, Marosi C, Königsbrügge O, Riedl J, Posch F, Lamm W, Lang IM, Pabinger I and Ay C: Association of complete blood count parameters, d-Dimer and soluble P-selectin with risk of arterial thromboembolism in patients with cancer. J Thromb Haemost: May 17, 2019 (Epub ahead of print).

37. Song D, Powles T, Shi L, Zhang L, Ingersoll MA and Lu YJ: Bladder cancer, a unique model to understand cancer immunity and develop immunotherapy approaches. J Pathol: May 18, 2019 (Epub ahead of print).

38. Meerson A, Eliraz Y, Yehuda H, Knight B, Crundwell M, Ferguson D, Lee BP and Harries LW: Obesity impacts the regulation of miR-10b and its targets in primary breast tumors. BMC Cancer 19: 86, 2019.

39. Zhang S, Wang J, Ghoshal T, Wilkins D, Mo YY, Chen Y and Zhou Y: lncRNA gene signatures for prediction of breast cancer intrinsic subtypes and prognosis. Genes (Basel) 9: 9, 2018.

40. Fialkova V, Vidomanova E, Balharek T, Marcinek J, Kudela E, Hanysova S, Visnovsky J, Dobrota D and Hatok J: DNA methylation as mechanism of apoptotic resistance development in endometrial cancer patients. Gen Physiol Biophys 36: 521-529, 2017.
41. Ma R, Feng N, Yu X, Lin H, Zhang X, Shi O, Zhang H, Zhang S, $\mathrm{Li} \mathrm{L}$, Zheng M, et al: Promoter methylation of Wnt/ $\beta$-Catenin signal inhibitor TMEM88 is associated with unfavorable prognosis of non-small cell lung cancer. Cancer Biol Med 14: 377-386, 2017.

42. Martinez-Garcia E, Lesur A, Devis L, Campos A, Cabrera S, van Oostrum J, Matias-Guiu X, Gil-Moreno A, Reventos J, Colas E, et al: Development of a sequential workflow based on LC-PRM for the verification of endometrial cancer protein biomarkers in uterine aspirate samples. Oncotarget 7: 53102-53115, 2016.

43. Chen X, Huang J, Li J, Han Y, Wu K and Xu P: Tra2betal regulates P19 neuronal differentiation and the splicing of FGF-2R and GluR-B minigenes. Cell Biol Int 28: 791-799, 2004.

44. Shiraishi E, Imazato H, Yamamoto T, Yokoi H, Abe $\mathrm{S}$ and Kitano T: Identification of two teleost homologs of the Drosophila sex determination factor, transformer-2 in medaka (Oryzias latipes). Mech Dev 121: 991-996, 2004.

45. Stoilov P, Daoud R, Nayler O and Stamm S: Human tra2-beta1 autoregulates its protein concentration by influencing alternative splicing of its pre-mRNA. Hum Mol Genet 13: 509-524, 2004.

46. Hofmann Y and Wirth B: hnRNP-G promotes exon 7 inclusion of survival motor neuron (SMN) via direct interaction with Htra2-beta1. Hum Mol Genet 11: 2037-2049, 2002.

(i)(3) This work is licensed under a Creative Commons cc) $\mathrm{EY}$ No NO Attribution-NonCommercial-NoDerivatives 4.0 International (CC BY-NC-ND 4.0) License. 